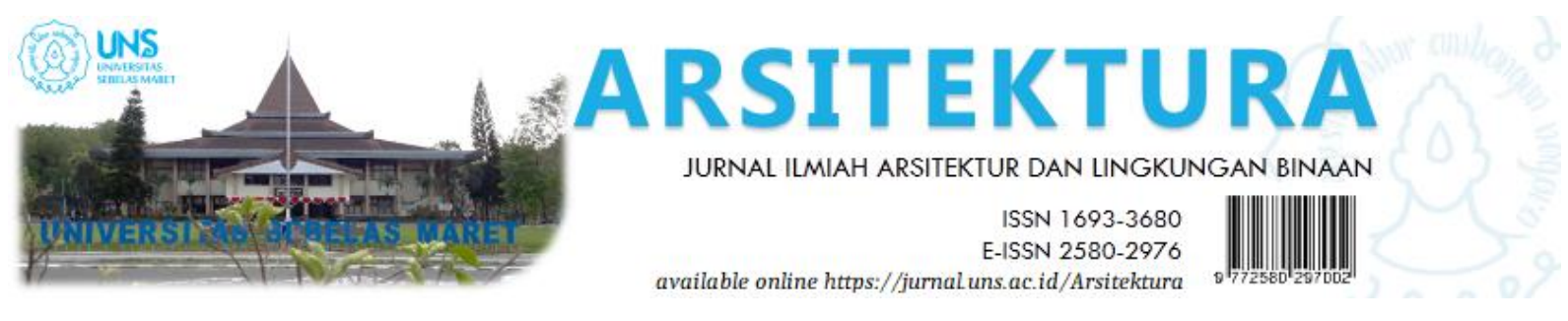

Volume 18 Issue 2 October 2020, pages:277-290

\title{
Kajian Biomorphic Architecture dalam Perancangan Oceanarium Pekanbaru
}

\author{
Study of Biomorphic Architecture \\ in the Design of Pekanbaru Oceanarium
}

\author{
Nurul Asyifa ${ }^{1 *}$, Yohannes Firzal ${ }^{2}$, Gun Faisal ${ }^{3}$ \\ Juru san Arsitektur, Fa kultas Teknik, Universitas Ria u ${ }^{1^{*}}$ \\ Nurul.asyifa3655@student.unri.ac.id \\ Jurusan Arsitektur, Fakultas Teknik, Universitas Riau ${ }^{2}$ \\ Jurusan Arsitektur, Fakultas Teknik, Universitas Riau ${ }^{3}$
}

DOI: https://doi.org/10.20961/arst.v18i2.42634

Received: July5, 2020 Revised:September 25, 2020 Accepted:September 28, 2020 Available online: October 31, 2020

\begin{abstract}
Pekanbaru is a city that is growing rapidly and becomes one of the cities that is frequently visited. But the tourist attraction by the city of Pekanbaru are still lacking. Besides that in the geographical triangle, the water region in Riau Province is bigger than the land area, so the water region in Riau Province has a very high potential. Buteducation aboutmarine life and conservation a re as that supportbiota protection in Riau province is still very least. Therefore, we need a public facility that is equipped with recreational, educational, and conservational needs. To actualize these public facilities, then will be designed an Oceanarium in Pekanbaru City. Oceanarium is a reservoir in a giant aquarium for the conservation of plants and marine biota that serves as a means of education, research, preservation, marine development, and exhibited as a means of recreation. The theme of the Oceanarium in Pekanbaru is Biomorphic Architecture. Biomorphic Architecture is part of architectural design that proposes allideas taken from organic life, by form, system, or movement. Through the concept of Ocean Life Dynamics, the characteristics of building functions can be made as recreationalfacilities, conservation, and education about life under the sea.
\end{abstract}

Keywords: Biomorphic Architecture, Oceanarium, Pekanbaru

\section{PENDAHULUAN}

\subsection{Latar Belakang}

Pekanbaru merupakan kota yang sedang berkembang pesat sebagai salah satu sentra ekonomi terbesar di Pulau Sumatera dan termasuk kota dengan tingkat pertumbuhan migrasi dan urbanisasi yang tinggi. Pekanbaru memiliki posisi yang strategis secara geografis dan dilintasi oleh Sungai Siak yang merupakan jalur perhubungan lalu lintas perekonomian masyarakat. Selain itu kota ini berada di jalur Lintas Timur Sumatera yang terhubung dengan beberapa kota besar di Sumatera (Santosa, 2018). Hal ini membuat Kota Pekanbaru menjadi salah satu kota yang sering dikunjungi. Pada bidang pariwisata, Kota Pekanbaru masih kekurangan fasilitas publik yang dapat mencakup kebutuhan rekreasi, edukasi, serta konservasi. 
Pemanfaatan ruang wilayah Provinsi berpedoman pada rencana struktur ruang, rencana pola ruang, dan perwujudan Kawasan Strategis Provinsi. Arahan pemanfaatan ruang wilayah Provinsi berisi indikasi program utama jangka menengah lima tahunan dalam kurun waktu Rencana Tata Ruang Wilayah Provinsi. Arahan pemanfaatan ruang dalam rangka perwujudan pola ruang dilakukan melalui perwujudan kawasan lindung dan perwujudan kawasan budidaya. Pengelolaan kawasan konservasi bertujuan untuk perlindungan keanekaragaman biota, tipe ekosistem, gejala keunikan alam serta pelestarian fungsi lindung dan tatanan lingkungan kawasan (peningkatan kualitas lingkungan sekitarnya dan perlindungan dari pencemaran), pengembangan pendidikan, rekreasi dan pariwisata (Peraturan Daerah Provinsi Riau Nomor 10 Tahun 2018 Tentang Rencana Tata Ruang Wilayah Provinsi Riau Tahun 2018-2038).

Provinsi Riau memiliki luas wilayah daratan sebesar 87.023,66 km² (Badan Pusat Statistik Provinsi Riau, 2020), sedangkan luas wilayah lautan di Provinsi Riau adalah sebesar 681.961,83 km² (Direktorat Jenderal Penguatan Daya Saing Produk Kelautan dan Perikanan Kementerian Kelautan dan Perikanan, 2018). Data tersebut menjelaskan bahwa wilayah perairan di Provinsi Riau lebih besar dibandingkan wilayah daratan, sehingga wilayah perairan di Provinsi Riau memiliki potensi yang sangat tinggi. Namun edukasi tentang kehidupan laut serta kawasan konservasi yang bertujuan untuk perlindungan keanekaragaman biota pada perairan Provinsi Riau masih sangat minim. Oleh karena itu diperlukan suatu fasilitas publik yang dapat menunjang kebutuhan tersebut yakni sebuah oceanarium.

Oceanarium merupakan wadah untuk memelihara tumbuhan dan biota-biota laut yang ingin dipamerkan dan digunakan sebagai sarana rekreasi, sekaligus menjadi sarana penelitian, pelestarian, serta pengembangan kelautan (Sanjaya, 2015). Fungsi oceanarium antara lain sebagai sarana konservasi yang memiliki peran global dalam bidang edukasi untuk mengenal serta mempelajari biota-biota laut yang hidup pada daerah tertentu, selain itu memiliki peran sebagai sarana penelitian yang menampilkan biota laut yang masih hidup maupun yang sudah mati untuk menambah pengetahuan tentang kehidupan bawah laut, serta sebagai sarana rekreasi yang memamerkan objek pamer berupa kehidupan bawah laut yang ditampilkan dengan akuarium-akuarium raksasa (Lange, 1955).

Kehadiran oceanarium di Pekanbaru sebagai fasilitas publik di bidang pariwisata memberi pemasukan besar bagi perkembangan serta kemajuan fasilitas rekreasi dan pendapatan daerah, memberi dampak positif bagi masyarakat di bidang edukasi, serta sebagai wadah pelestarian biota laut yakni di bidang konservasi. Oceanarium berkaitan erat dengan alam karena memiliki dampak yang besar bag $i$ kelestarian alam. Oleh karena itu perancangan oceanarium Pekanbaru memerlukan pendekatan desain yang memiliki karakter serta unsur kehidupan alam. Pendekatan desain yang tepat untuk oceanarium Pekanbaru adalah Biomorphic Architecture.

Biomorphic Architecture merupakan pendekatan desain arsitektural yang menerapkan segala ide yang diambil dari kehidupan organik, baik berdasarkan bentuk, sistem maupun pergerakan. Penggunaan pendekatan desain ini sangat berhubungan erat dengan visual tampilan fisik bangunan dalam sebuah perancangan. Kesan yang ditimbulkan dari biomorphic architecture adalah bentuk yang abstrak, unik, dan dinamis. Selain itu, pendekatan desain ini sangat memperhatikan keberlanjutan dan isu global dengan meminimalisir permasalahan dengan menggunakan material lokal dan material pendukung yang memiliki struktur ringan. Biomorphic Architecture pada dasarnya berbasis ekologi dan metafora, yang keduany a memiliki kesamaan dalam proses pendekatan rancangan bentuk berdasarkan analisis bentuk lain yang dikaitkan (Ishomuddin, 2013).

Tulisan ini mengandung permasalahan antara lain bagaimana menerapkan prinsip desain Biomorphic Architecture pada Oceanarium Pekanbaru, selain itu permasalahan bagaimana penerapan konsep dengan pendekatan desain pada perencanaan Oceanarium Pekanbaru.

Berdasarkan uraian di atas tulisan ini bertujuan menerapkan tema Biomorphic Architecture pada elemen serta aspek perancangan 
Oceanarium Pekanbaru, dan menerapkan konsep yang dapat memecahkan permasalahan pada perencanaan Oceanarium Pekanbaru.

\subsection{Oceanarium}

Oceanarium berasal dari dua kata, yakni "ocean" dan "rium". "Ocean" merupakan Bahasa Inggris yang berarti samudera atau lautan. Sedangkan kata "rium" berasal dari penggalan kata aquarium yang memiliki arti wadah atau tempat.

Menurut beberapa sumber, pengertian oceanarium antara lain merupakan akuarium besar berisikan air laut yang terdapat biotabiota laut, dimana dijadikan sarana pembelajaran sekaligus menjadi sarana hiburan atau rekreasi (Murray, 2015). Selain itu menurut Harcourt (2010), oceanarium adalah akuarium air asin yang besar untuk ikan dan hewan laut. Encyclopedia Britannica (2012) menjelaskan pengertian oceanarium adalah akuarium air asin yang menampilkan hewan laut dan tanaman, terutama hewan dan tanaman yang hidup di samudera, atau di zona pelagis, ikan, dan mamalia. Oceanarium berfungsi sebagai fasilitas hiburan untuk umum, sarana pendidikan, serta sarana penelitian ilmiah (Augustyn \& Bauer, 2013).

Berdasarkan beberapa definisi dari oceanarium tersebut maka dapat disimpulkan bahwa oceanarium merupakan suatu wadah dalam bentuk aquarium raksasa yang berisikan biota laut beserta ekosistemnya dan memiliki fasilitas-fasilitas yang dapat menunjang kegiatan di dalamnya.

Fungsi oceanarium menurut Lange (1955) antara lain sebagai sarana konservasi yang memiliki peran global dalam bidang edukasi untuk mengenal serta mempelajari biota-biota laut yang hidup pada daerah tertentu. Fungsi lainnya adalah sebagai sarana penelitian yang menampilkan biota laut yang masih hidup maupun yang sudah mati untuk menambah pengetahuan tentang kehidupan bawah laut. Selain itu oceanarium merupakan sarana rekreasi yang memamerkan objek pamer berupa kehidupan bawah laut yang ditampilkan dengan akuarium-akuarium raksasa.

Dapat disimpulkan bahwa oceanarium berfungsi sebagai sarana rekreasi yang menampilkan objek pamer kehidupan laut, selain itu juga sebagai sarana konservasi bagi biota laut agar tetap terjaga dan lestari, serta berfungsi sebagai sarana edukasi yakni sebagai tempat penelitian dan penambah wawasan yang dapat dikunjungi berbagai kalangan.

\subsection{Biomorphic Architecture}

Biomorphic berasal dari dua suku kata yakni Bios yang artinya kehidupan dan Morphology yang berarti bentuk atau sistem. Biomorphic Architecture merupakan pendekatan desain arsitektural yang menerapkan segala ide yang diambil dari kehidupan organik, baik berdasarkan bentuk, sistem maupun pergerakan. Penggunaan pendekatan desain ini sangat berhubungan erat dengan visual tampilan fisik bangunan dalam sebuah perancangan. Biomorphic architecture menciptakan kesan bentuk yang abstrak, unik, dan dinamis (Ishomuddin, 2013).

Desain biomorphic adalah desain yang memiliki bentuk dan massa abstrak organik yang tampak dinamis, bersemangat, dan jauh dari bentuk geometris (Taha, 2019). Pendekatan ini memberikan simbol bahwa tubuh makhluk hidup memiliki konsep arsitektur (Akbar, 2019). Biomorphic Architecture ini pada dasarnya berbasis ekologi dan metafora (Ishomuddin, 2013). Keduanya memiliki persamaan dalam proses pendekatan rancangan bentuk berdasarkan analisis bentuk lain yang dikaitkan.

Biomorphic architecture lebih terfokus terhadap proses dinamik yang berkaitan dengan proses pertumbuhan serta perubahan pada makhuk hidup (Supardjo, 2014). Biomorphic menekankan pada proses terbentuknya dan pembentukan wujud arsitektural. Menurut Agkathidis (2016), biomorphic architecture menggambarkan sintesis kreatif yang menjembatani kesenjangan antara surealisme dan seni abstrak. Biomorphic architecture dikaitkan dengan fluida, bentuk organik dalam seni, arsitektur, desain, serta sering digunakan untuk menggambarkan bentuk dan pola yang terinspirasi oleh alam.

Analogi biomorphic architecture diartikan bahwa arsitektur sebagai makhluk hidup atau arsitektur itu hidup. Ciri makhluk hidup salah 
satunya ialah tumbuh dan berkembang. Pertumbuhan dan perkembangan pada suatu desain arsitektur dapat direncanakan. Gagasan pertumbuhan tersebut bisa dilakukan secara vertikal atau horizontal. Jika perkembangan karya arsitektur tersebut tidak direncanakan maka perkembangannya bisa secara sporadis yaitu tidak beraturan. Biomorphic architecture menegaskan bahwa bangunan bukan merupakan suatu proses estetika, namun bangunan merupakan suatu proses biologis (Supardjo, 2014).

Biomorphic Architecture adalah salah satu tema dalam pendekatan arsitektur yang memiliki prinsip kepedulian terhadap lingkungan (alam), di mana pendekatan ini lahir dari gagasan tentang pentingnya alam dan berorientasi pada lingkungan, termasuk iklim. Ide dasar dalam desain biomorphic architecture merupakan proses kolaborasi antara hubungan manusia dan alam yang dapat diterapkan pada bentuk, bahan, struktur serta mekanismenya (Ishomuddin \& Fikriarini, 2016).

Prinsip-prinsip yang digunakan pada biomorphic architecture terdiri dari prinsip bentuk, prinsip struktur dan material, serta prinsip berkelanjutan. Bentuk-bentuk dalam Biomorphic Architecture dapat diperoleh melalui analogi atau metafora dari bentukbentuk alam. Bentuk dari alam cenderung lebih dinamis serta jauh dari bentuk geometris. Alam tidak hanya dicontoh dari bentuknya saja, namun bagaimana prinsip alam itu bekerja (Rasikha, 2009). Prinsip struktur yang digunakan pada biomorphic architecture lebih estetis dengan mengambil bentuk-bentuk dari alam. Sedangkan dari segi penggunaan material bangunan, biomorphic architecture memiliki kecenderungan dalam pemakaian material alami (lokal), material berbahan ringan seperti membrane, dan material lain yang mendukung bentuk- bentuk kurvilinier (Rasikha, 2009). Biomorphic architecture selalu mengalami perkembangan dalam desain terutama pada struktur, yakni struktur pneumatik (memiliki gaya tarik dan tekan) serta bersel banyak (unsur biologis) (Angkouw \& Kapugu, 2012). Selain itu biomorphic architecture memiliki prinsip berkelanjutan yakni sangat memperhatikan kesadaran ekologi guna menciptakan sebuah perancangan yang ramah lingkungan.

\subsection{Preseden Oceanarium}

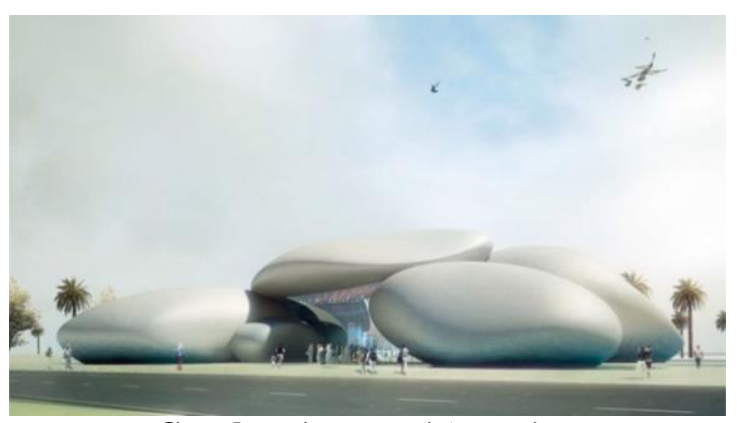

Gambar 1. Ba tumi Aquarium

Sumber: Jordana, 2010

Batumi Aquarium merupakan sebuah oceanarium yang berlokasi di Str Rustaveli, Batumi, Republik Georgia. Oceanarium ini memiliki luas $2000 \mathrm{~m}^{2}$. Proyek ini selesai dibangun pada tahun 2013. Batumi adalah kota di Provinsi Adjara/Ajaria Barat Daya yang terletak bersebelahan dengan Laut Hitam.

Batumi Aquarium terinspirasi oleh kerikil khas pantai Batumi dimana residu laut yang dinamis terus membentuk tepi pantai sepanjang ribuan tahun. Bangunan ini terletak di pelabuhan Georgia Batumi dan mempunyai ciri khas yang menonjol sebagai formasi batuan ikonik yang dapat terlihat dari darat dan laut (Jordana, 2010).

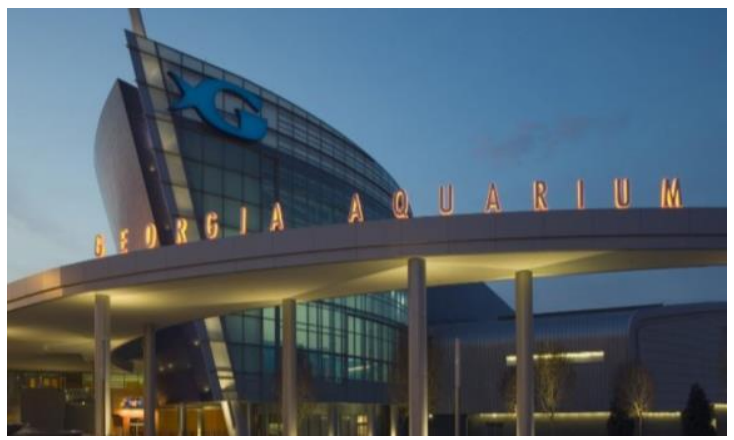

Gambar 2. Georgia Aquarium

Sumber:https://bit.ly/2UO35GM

Georgia Aquarium merupakan sebuah akuarium yang berlokasi di Atlanta, Georgia. Bangunan ini dirancang oleh arsitek Thompson, Ventulett,Stainback, Atlanta, GA. Akuarium ini memiliki luas area $50.000 \mathrm{~m}^{2}$. Proyek ini dibuka untuk umum pada 2005. Akuarium ini merupakan akuarium terbesar di dunia pada 2005 hingga 2012. 
Georgia Aquarium terletak di tengah kota sehingga menggunakan sistem sirkulasi air akuarium tertutup. Sistem ini merupakan sistem daur ulang dengan mengganti volume air beberapa kali sehari melalui penyaringan biologis, kimia, dan mekanis (Coffeen et al., 2015). Akuarium ini memiliki volume tangki sebesar $32.000 \mathrm{~m}^{3}$ yang terdiri dari air laut dan air tawar, berisikan 120.000 hewan laut yang terdiri dari 500 spesies biota laut (Sanjaya, 2015).

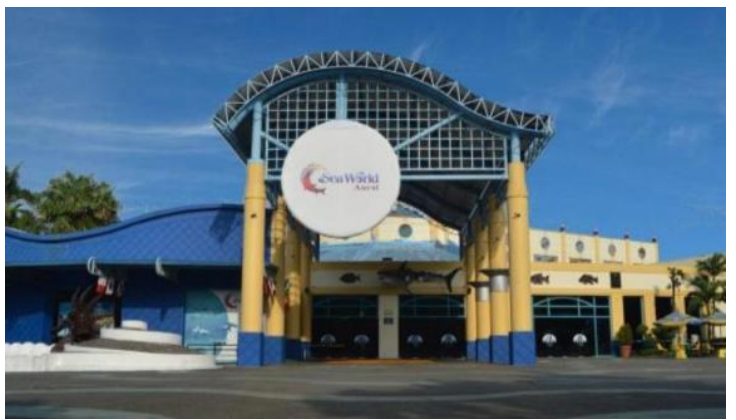

Gambar 3. Sea world Ancol

Sumber:https://id.pinterest.com/

Seaworld Indonesia atau yang biasa disebut Seaworld Ancol merupakan sebuah oceanarium yang terletak di kawasan Taman Impian Jaya Ancol Jakarta, Jakarta Utara, Indonesia. Seaworld Ancol dibangun pada 1992 dan dibuka pada 1994. Luas area Seaworld Ancol adalah sebesar 3 ha dengan luas bangunan utama sebesar $4.500 \mathrm{~m}^{2}$.

Fasilitas-fasilitas yang ada pada Seaworld Ancol sangat beragam. Terdapat beberapa jenis akuarium serta beberapa fasilitas penunjang. Akuarium yang disediakan pada bangunan ini antara lain adalah akuarium utama, akuarium air tawar, akuarium hiu, terowongan antasena, serta kolam sentuh. Fasilitas-fasilitas penunjang yang disediakan untuk pengunjung antara lain adalah theater, perpustakaan, museum, komputer layar sentuh, food court, serta toko cenderamata (Yulianingsih, 2011).

Kesimpulan yang dapat diambil dari ketiga preseden oceanarium tersebut yaitu terdapat beberapa fasilitas yang harus dimiliki dalam sebuah perancangan oceanarium. Fasilitasfasilitas tersebut antara lain berupa akuarium, terowongan antasena, kolam sentuh, serta fasilitas yang dapat menunjang kebutuhan dari fungsi sebuah oceanarium yang merupakan sarana rekreasi, edukasi, serta konservasi.

\subsection{Preseden Biomorphic Architecture}

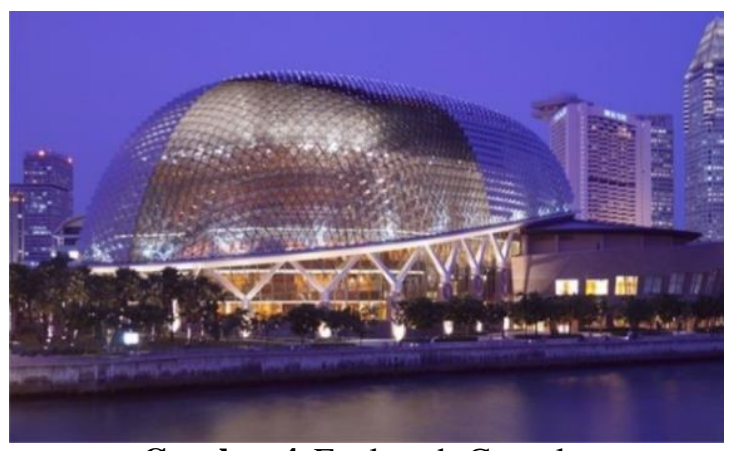

Gambar 4. Esplanade Complex

Sumber: Tham, 2019

Esplanade Complex merupakan Venue untuk pertunjukan seni dan budaya yang berlokasi di Esplanade Drive, Marina Bay, Singapura. Bangunan ini terletak di pinggir Teluk Marina dan membatasi pusat sipil dan distrik bersejarah Singapura. Esplanade Complex memiliki luas area sebesar $75.186 \mathrm{~m}^{2}$. Desain ini dirancang oleh DP Architect, James Stirling, dan Michael Wilford.

Bentuk atapnya menyerupai kulit durian yang terdiri dari panel-panel yang berjajar seperti matahari. Di atas kisi-kisi, lapisan kedua dari panel aluminium menciptakan semacam paruh burung yang berubah arah rata atau naik, memberikan penutup yang bersisik (Carone, 2018). Selain itu terdapat kolom-kolom untuk menyangga bagian cladding atap berbentuk batang pohon bercabang. Struktur penyangga tersebut menggunakan sistem yang sama seperti sistem pohon.

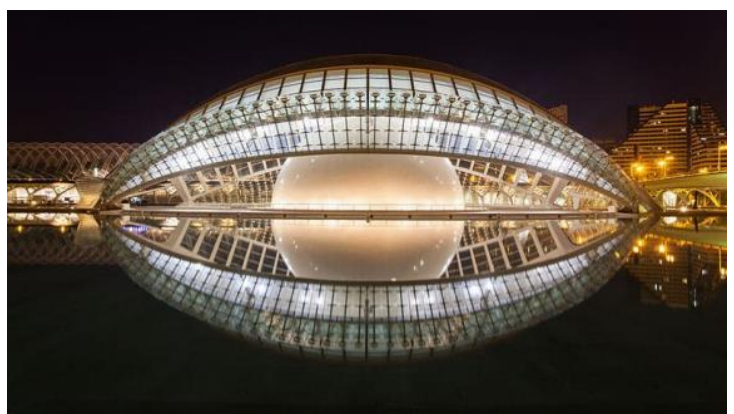

Gambar 5. L'Hemisferic

Sumber: https://www.focusclinics.com/

L'Hemisferic merupakan sebuah planetarium dan laserium yang berlokasi di Valencia, Spanyol. Bangunan ini dirancang oleh Santiago Calatrava dan resmi dibuka pada tahun 1998. 
Konsep dari L'Hemisferic ini diambil dari mata manusia yang dapat 'melihat semua'. Konsep ini melambangkan manusia yang melihat dan mengamati dunia, langit, dan bintang-bintang sesuai dengan fungsi bangunan sebagai planetarium. Di sekeliling bangunan terdapat kolam dengan dasar kaca seluas $24.000 \mathrm{~m}^{2}$ yang berfungsi untuk menciptakan pantulan sehingga terbentuk gambar mata yang utuh.

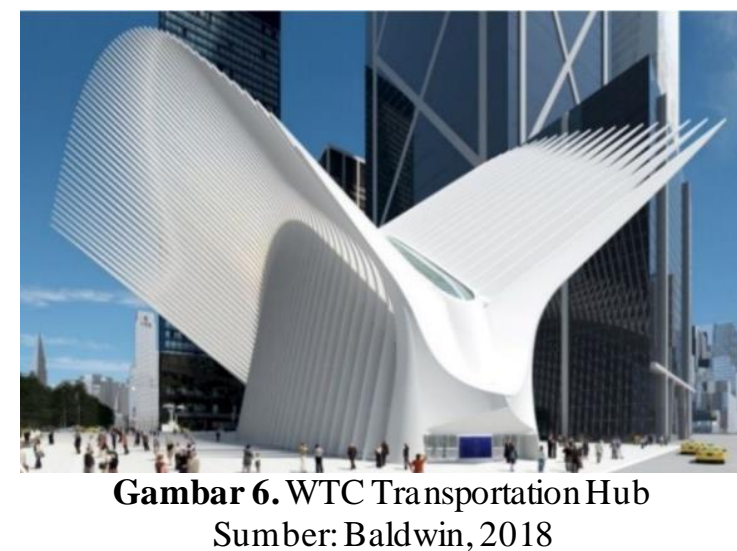

World Trade Center (WTC) Transportation Hub merupakan sebuah bangunan dengan fungsi sebagai pusat transportasi yang dirancang oleh arsitek ternama Santiago Calatrava. Bangunan ini berlokasi di New York, Amerika Serikat. WTC Transportation Hub selesai dibangun pada tahun 2016 .

Konsep dari World Trade Center Transportation Hub ini terinspirasi dari seekor burung yang dilepas dari tangan seorang anak. Santiago Calatrava juga mencari inspirasi dalam merancang WTC Transportation Hub ini dengan preseden dua bangunan yang sangat menarik baginya yakni Grand Central Terminal dan Pennsylvania Station (Baldwin, 2018).

Kesimpulan yang dapat diambil dari ketiga preseden biomorphic architecture ini antara lain, pada perancangan dengan pendekatan desain biomorphic architecture harus mengambil konsep dari kehidupan alam dan makhluk hidup yang diterapkan baik dalam segi bentuk, material, struktur, fasad, serta rencana tapak.

\section{METODE}

\subsection{Paradigma Perancangan}

Oceanarium merupakan suatu wadah dalam bentuk akuarium raksasa yang berisikan biota laut beserta ekosistemnya dan memiliki fasilitas-fasilitas yang dapat menunjang kegiatan di dalamnya. Oceanarium berfungsi sebagai sarana edukasi, rekreasi, serta konservasi. Pemilihan fungsi dilatarbelakangi berdasarkan kurangnya fasilitas publik di bidang pariwisata, kurangnya edukasi mengenai biota laut, serta sebagai wadah pelestarian biota laut yang mulai terancam keberadaannya.

Kehadiran Oceanarium di Pekanbaru sebagai fasilitas publik di bidang pariwisata memberi pemasukan besar bagi perkembangan serta kemajuan sarana rekreasi dan pendapatan daerah, memberi dampak positif bagi masyarakat di bidang edukasi, serta sebagai wadah pelestarian biota laut yakni di bidang konservasi.

\subsection{Lokasi Perancangan}

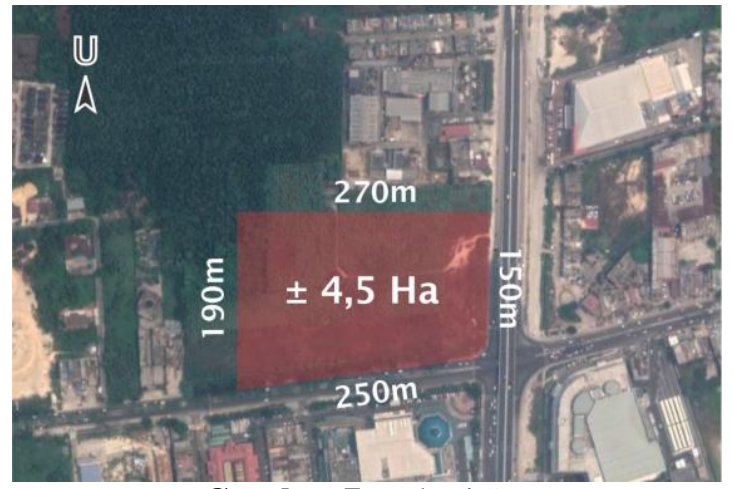

Gambar 7.Lokasi Site

Sumber: https://earth.google.com/web

Lokasi site perancangan Oceanarium Pekanbaru berada di Jalan Tuanku Tambusai, Pekanbaru, Riau. Site perancangan ini memiliki luas sebesar $\pm 4,5$ ha, dengan KDB sebesar $50 \%$. Kondisi eksisting site merupakan lahan kosong yang memiliki kontur relatif datar.

\subsection{Strategi Perancangan}

Penyusunan strategi perancangan Oceanarium Pekanbaru dengan Pendekatan Biomorphic Architecture menggunakan beberapa strategi dalam pengambilan data yaitu dimulai dari 
analisa Kota Pekanbaru, studi literatur Biomorphic Architecture, mencari pengertian dan fungsi Oceanarium, analisa fungsi dan kegiatan, analisa site, penzoningan, program ruang, konsep, lansekap, bentukan massa, struktur, utilitas, fasad, hingga mendapatkan hasil desain.

\subsection{Metode Pengumpulan Data}

Pada perencanaan oceanarium ini digunakan beberapa metode untuk mengumpulkan data. Data yang dibutuhkan dalam perancangan terdiri dari dua macam data, yaitu data primer yang didapat dari survey lapangan (observasi) dan dokumentasi, serta data sekunder yang didapat dari studi pustaka dan studi banding.

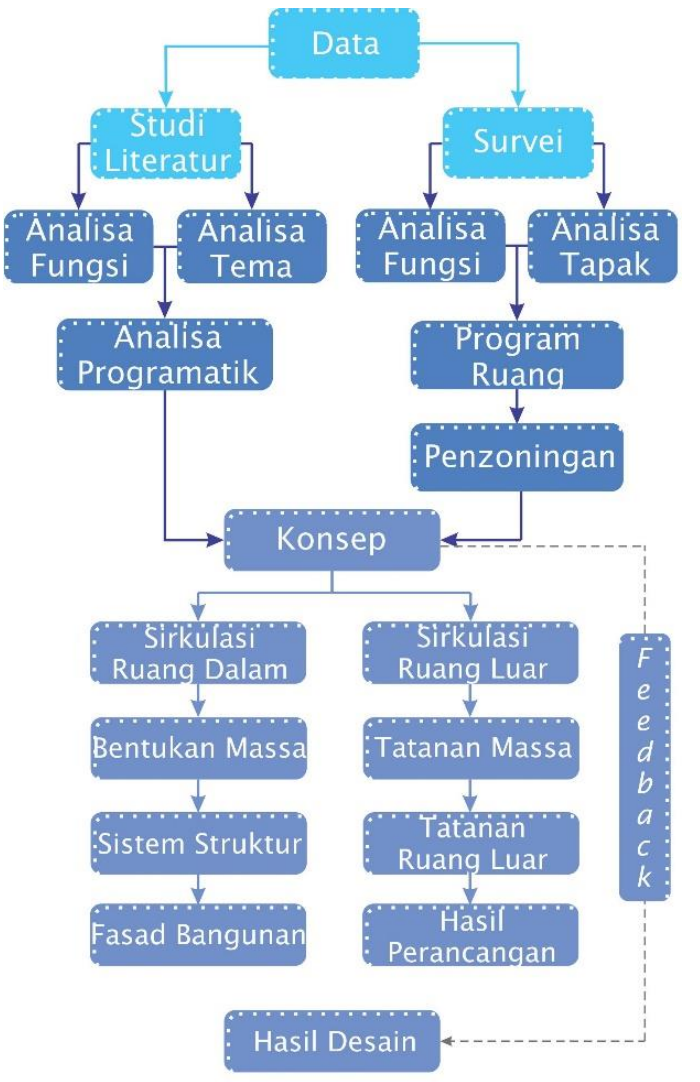

Pengumpulan Data

Analisa

Feedback

Gambar 8. Ba gan Alur Perancangan

\section{HASIL DAN PEMBAHASAN}

\subsection{Kebutuhan Ruang}

Berdasarkan analisis kegiatan dihasilkan kebutuhan ruang yang terdapat pada mapping serta tabel yang kemudian akan didapatkan program-program ruang yang akan dilakukan pada setiap ruangan. Besaran ruang perancangan oceanarium didapatkan dari kebutuhan ruang serta program-program ruang tersebut yang dijelaskan pada tabel 1 .

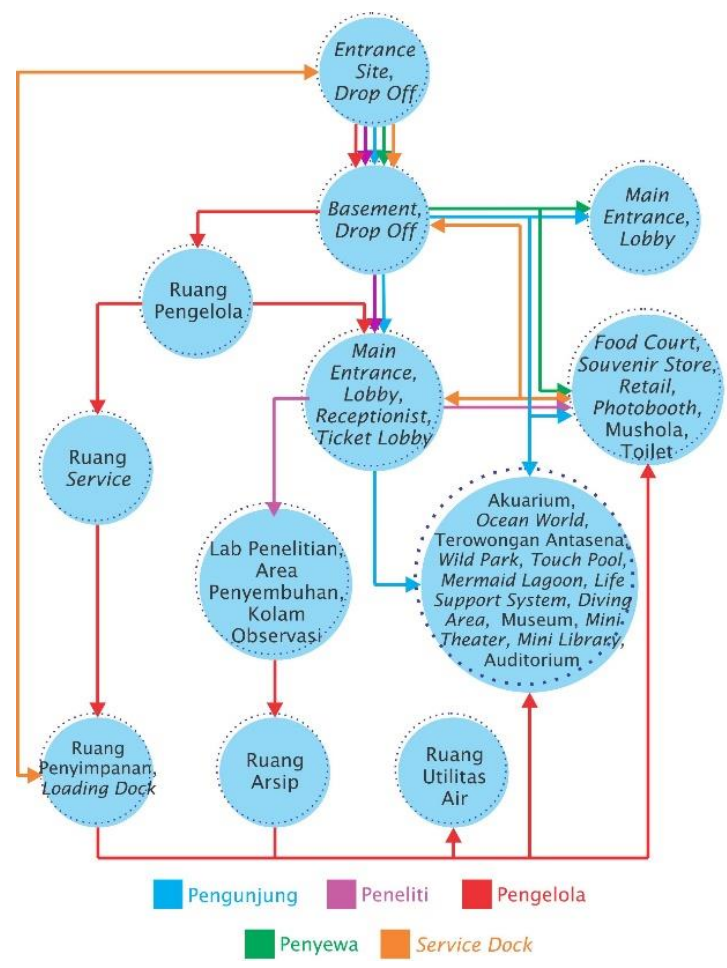

Gambar 9. Mapping Kebutuhan Ruang

Tabel 1. Kebutuhan Ruang

\begin{tabular}{cc}
\hline Nama Ruang & Luasan $\left.\mathbf{( m}^{\mathbf{2}}\right)$ \\
\hline Area Utama & $4.878,12 \mathrm{~m}^{2}$ \\
Area Konservasi & $400,4 \mathrm{~m}^{2}$ \\
Area Pengelola & $950,3 \mathrm{~m}^{2}$ \\
Area Servis & $378,3 \mathrm{~m}^{2}$ \\
Area Parkir & $2.740,4 \mathrm{~m}^{2}$ \\
Ruang Luar & $10.530 \mathrm{~m}^{2}$ \\
\hline Total & $19.877,52 \mathrm{~m}^{2}$ \\
\hline
\end{tabular}

\subsection{Penzoningan}

Pembagian zoning pada site secara umum terdiri dari zona publik, zona semi-publik, dan zona privat. Zona publik terdiri dari zona rekreasi, edukasi, dan komersil. Zona semipublik terdiri dari zona konservasi. Sedangkan zona privat terdiri dari zona pengelola dan zona service. 


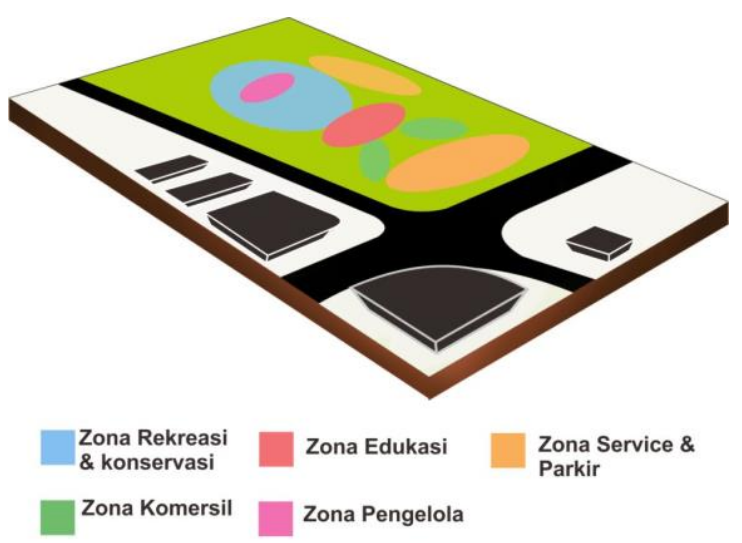

Gambar 10. Penzoningan

\subsection{Penerapan Prinsip Biomorphic Architecture}

Perancangan Oceanarium Pekanbaru ini menggunakan teori pendekatan Biomorphic Architecture, yang memiliki prinsip-prinsip yang dijelaskan pada tabel 2 berikut.

Tabel 2. Analisis Penerapan Prinsip Desain Biomorphic Architecture ke Bangunan

\begin{tabular}{|c|c|}
\hline \multicolumn{2}{|c|}{$\begin{array}{c}\text { Analisis Penerapan Prinsip Desain Biomorphic } \\
\text { Architecture ke Bangunan }\end{array}$} \\
\hline $\begin{array}{l}\text { Prinsip } \\
\text { Biomorphic } \\
\text { Architecture }\end{array}$ & Penerapan \\
\hline Bentuk & $\begin{array}{l}\text { Penerapan bentuk dari alam yang } \\
\text { dinamis yakni transformasi dari } \\
\text { bentuk ekor paus dan air laut yang } \\
\text { merupakan salah satu simbol dari } \\
\text { kehidupan laut. }\end{array}$ \\
\hline Struktur & $\begin{array}{l}\text { Struktur menggunakan space frame } \\
\text { agar dapat lebih estetis, serta dapat } \\
\text { mendukung bentuk- bentuk } \\
\text { kurvilinier sesuai dengan konsep } \\
\text { yang diterapkan. }\end{array}$ \\
\hline Material & $\begin{array}{l}\text { Lebih banyak menggunakan } \\
\text { material alami seperti kayu pada } \\
\text { interior bangunan, batu alam, } \\
\text { material berbahan ringan seperti } \\
\text { membrane, dan material yang } \\
\text { mendukung bentuk kurvilinier. }\end{array}$ \\
\hline Berkelanjutan & $\begin{array}{l}\text { Penerapan efisiensi penggunaan } \\
\text { energi yakni dengan memanfaatkan } \\
\text { cahaya matahari sebagai } \\
\text { pencahayaan alami di siang hari. } \\
\text { Selain itu pemanfaatan vegetasi } \\
\text { pada site, serta penggunaan elemen } \\
\text { air. }\end{array}$ \\
\hline
\end{tabular}

\subsection{Gaya Bangunan}

Gaya bangunan yang diterapkan pada oceanarium Pekanbaru ini merupakan karakteristik dari prinsip-prinsip pada tema rancangan yakni Biomorphic Architecture. Prinsip-prinsip desain tersebut diterapkan melalui bentukan massa, struktur bangunan, serta material yang digunakan.

Hasil dari kombinasi ciri dan prinsip desain Biomorphic Architecture pada bangunan oceanarium Pekanbaru dapat menciptakan hubungan terhadap kehidupan bawah laut melalui arsitektur dan lingkungan sekitar.

\subsection{Gubahan Massa}

Gubahan massa oceanarium Pekanbaru ini berupa single mass dengan bentuk yang didapatkan sesuai dengan kebutuhan fungsi, prinsip Biomorphic Architecture, serta konsep yang akan diterapkan ke dalam bangunan. Gubahan massa ditentukan dari kebutuhan ruang yakni dari area utama hingga area bawah air. Area bawah air / Ocean World terletak di bawah kolam agar konsep yang diterapkan dapat muncul di semua elemen / aspek perancangan termasuk area tersebut.

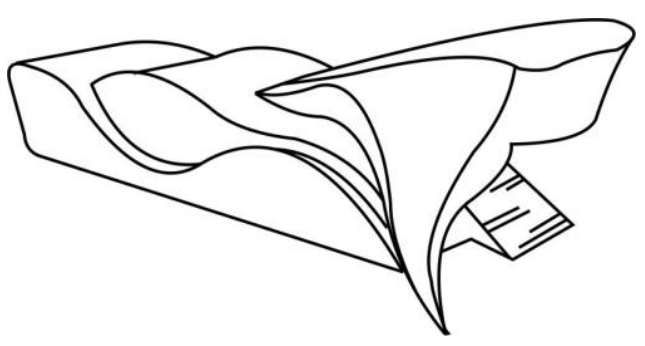

Gambar 11. Gubahan Massa

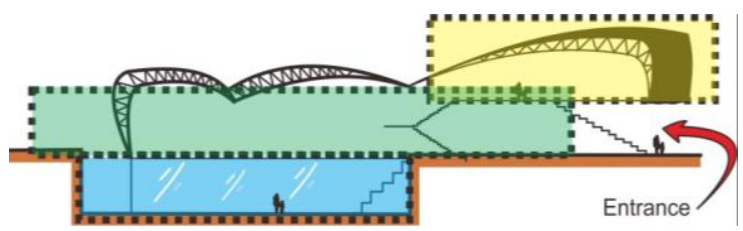

Gambar 12. Potongan Gubahan Massa

\subsection{Konsep}

Konsep dasar yang digunakan pada Oceanarium Pekanbaru ini adalah Ocean Life Dynamics. Konsep tersebut memiliki makna bentuk, sistem, maupun pergerakan dinamis yang ada pada kehidupan bawah laut. 


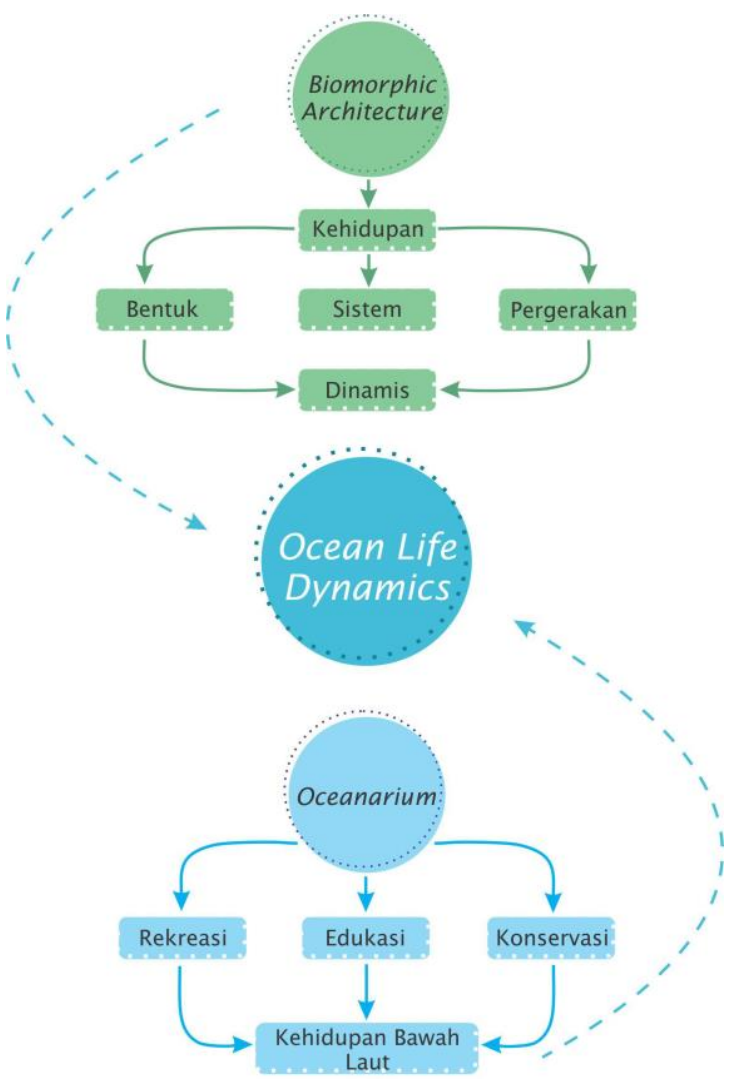

Gambar 13. Konsep Dasar

Bentuk dinamis didapatkan dari penggunaan bentuk-bentuk lengkung/kurvilinier, miring, variasi bentuk yang cukup beragam, dan olahan fasad yang cukup variatif. Bentuk yang dinamis tersebut diterapkan pada elemenelemen yang ada pada perancangan. Penerapan konsep Ocean Life Dynamics ini dapat mewujudkan karakteristik dari fungsi bangunan yakni sebagai sarana rekreasi, konservasi, serta edukasi mengenai kehidupan bawah laut.

\subsection{Konsep Bentukan}

Konsep bentukan pada Oceanarium Pekanbaru ini diambil dari salah satu biota laut yang merupakan salah satu simbol dari kehidupan bawah laut yakni ekor paus. Bentuk dan pergerakan ekor paus saat muncul ke permukaan air laut dan menghempas merupakan salah satu proses dinamik yang berhubungan dengan organisme. Bentuk ini sangat berkaitan erat dengan konsep dasar dari rancangan Oceanarium Pekanbaru yakni Ocean Life Dynamics.

Bentuk dan pergerakan ekor paus saat muncul ke permukaan dan menghempas air laut tersebut ditransformasikan menjadi bentuk dan gubahan bangunan Oceanarium Pekanbaru melalui beberapa tahap.

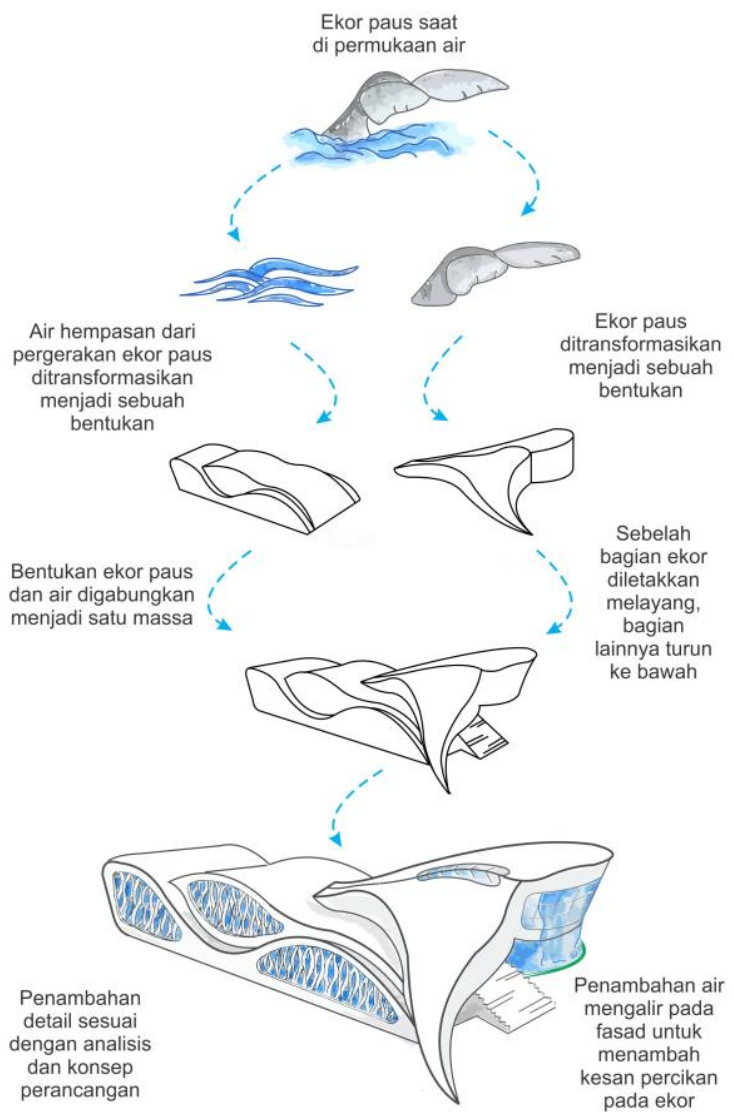

Gambar 14. Konsep Bentukan

\subsection{Konsep Fasad}

Konsep fasad yang digunakan pada bangunan Oceanarium Pekanbaru diambil dari tetesan air pada ekor paus yang menghempas. Fasad tersebut diletakkan pada dinding bangunan. Pada sisi lain bangunan, fasad kaca diberikan air mengalir yang menggambarkan percikan air pada ekor.

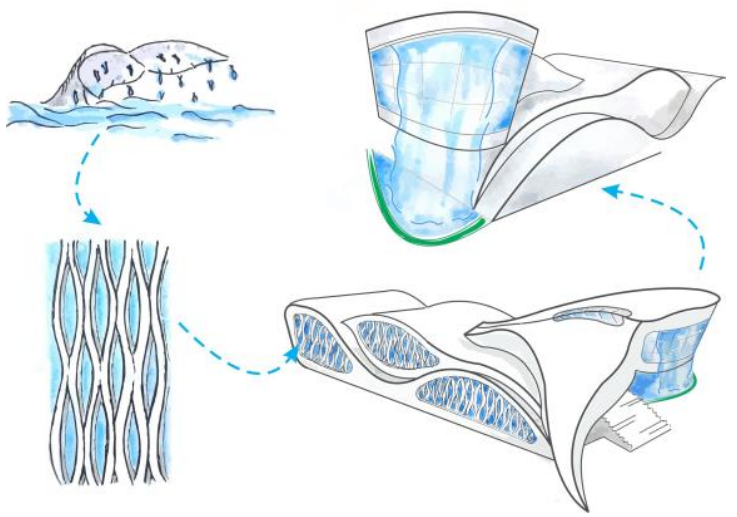

Gambar 15. KonsepFasad 


\subsection{Konsep Interior}

Konsep interior yang diterapkan pada bangunan Oceanarium Pekanbaru ini menggunakan nuansa bawah laut. Pada Ocean World / Area Bawah Air, akuarium disajikan secara langsung ke kolam yang ada pada site agar pengunjung dapat merasakan langsung suasana kehidupan bawah laut.

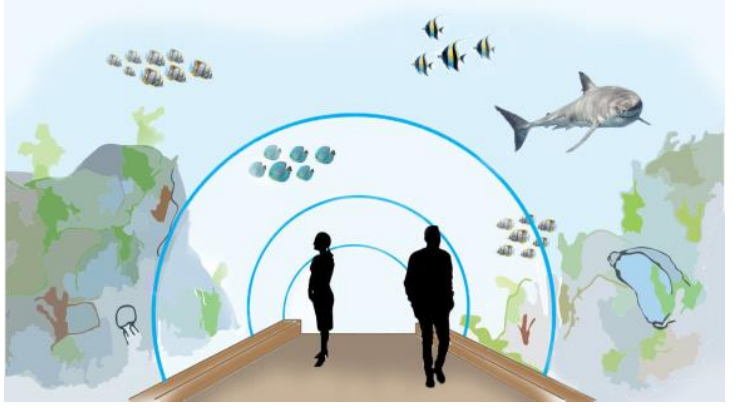

Gambar 16. Interior pada Area Ocean World

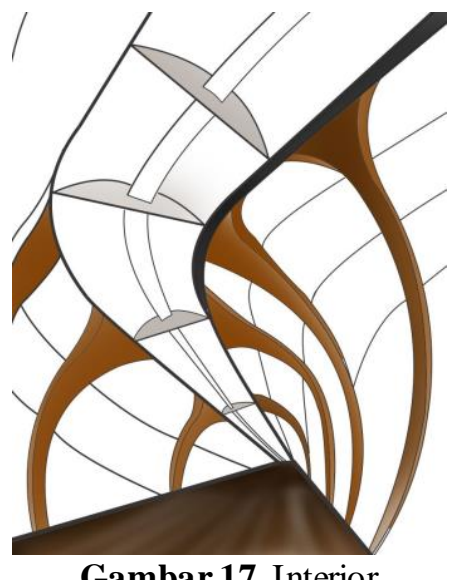

Gambar 17. Interior

\subsection{Struktur dan Konstruksi}

Struktur yang digunakan dipilih berdasarkan fungsi bangunan yakni sebagai area pamer serta berdasarkan tema rancangan yakni Biomorphic Architecture yang memiliki prinsip bentuk yang lebih dinamis sehingga bangunan ini menggunakan struktur bentang lebar. Struktur bentang lebar yang digunakan adalah space frame. Struktur ini memiliki kriteria bentangan yang relative besar, sehingga memungkinkan variasi bentuk atap yang lebih luas. Struktur space frame digunakan sebagai penahan beban atap pada seluruh bagian bangunan.

Pada struktur bawah digunakan pondasi pile dikarenakan struktur ini kuat dan sangat cocok untuk bangunan besar. Pondasi ini dapat mendukung beban berat dari bangunan yang berlantai banyak.

Struktur dan konstruksi akuarium yang digunakan pada perancangan antara lain akuarium bentuk bulat, silinder, diorama, kubus, serta akuarium utama dan terowongan antasena yang berada di Ocean World / Area Bawah Air. Struktur yang digunakan pada terowongan antasena juga ditumpu dengan pondasi pile.

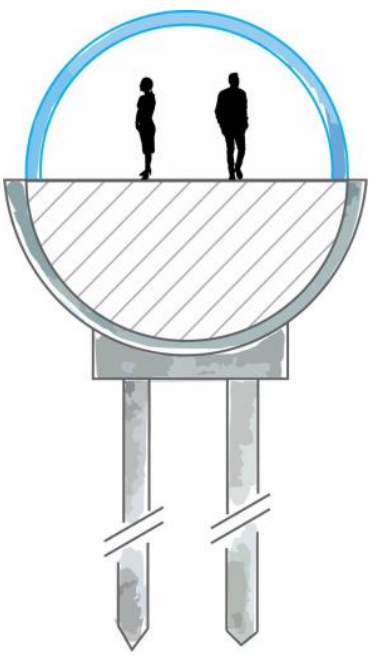

Gambar 18. Struktur Terowongan Antasena

\subsection{Material}

Material yang akan digunakan pada bangunan Oceanarium Pekanbaru diterapkan sesuai dengan material yang digunakan pada prinsip desain dari pendekatan Biomorphic Architecture yakni berupa material alam (lokal), material berbahan ringan, dan material yang mendukung bentuk- bentuk kurvilinier.

Material kayu diterapkan pada interior seperti lantai, plafond, serta beberapa bagian lain pada bangunan. Material kaca digunakan pada akuarium, bagian-bagian bangunan seperti skylight, fasad bangunan agar cahaya matahari dapat masuk sebagai pencahayaan alami. Material acrylic digunakan sebagai pengganti material kaca pada akuarium. Material beton diterapkan pada dinding bangunan. Material baja diterapkan sebagai struktur utama dari bangunan. Material ACP (Alumunium Composit Panel) diterapkan pada bagian fasad. Batu alam andesit diterapkan pada lantai dan pedestrian. 


\subsection{Sistem Pencahayaan}

Penerapan prinsip berkelanjutan Biomorphic Architecture pada bangunan ini salah satunya terdapat pada sistem pencahayaan yakni efisiensi penggunaan energi dengan pencahayaan alami yang memanfaatkan cahaya matahari masuk melalui bukaan dan fasad kaca pada bangunan. Cahaya yang berlebih dapat dikurangi dengan penggunaan material kaca yang blur, shading, dan perletakkan bukaannya. Selain itu pencahayaan alami dapat diperoleh dari penggunaan skylight serta penerapan heat insulted glass yang merupakan material kaca transparan berfungsi untuk mengurangi kalor panas tanpa mengurangi intensitas cahaya yang masuk ke dalam bangunan.

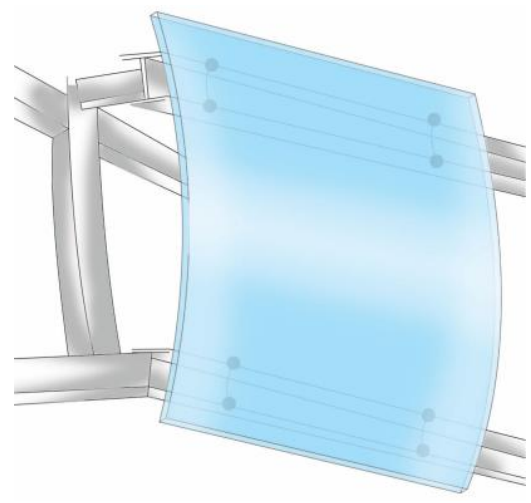

Gambar 19. Heat Insulted Glass

Teknik pencahayaan buatan yang digunakan pada perancangan ini antara lain uplight, downlight, hidden light, frontlight, dan light mapping.

Pencahayaan uplight diletakan di sudut lantai dapat digunakan sebagai petunjuk jalan ketika didalam area pamer. Pencahayaan downlight digunakan untuk memberikan pencahayaan yang merata pada ruangan, penggunaan pencahayaan downlight pada objek pamer dapat meningkatkan nilai estetika objek pamer. Selain diletakkan pada ruangan, pencahayaan downlight diletakkan pada beberapa akuarium. Pencahayaan hidden light digunakan pada akuarium yang ada pada ruang pamer untuk mempertegas dan memberi list pada bagian tertentu, contohnya pada akuarium individu. Pencahayaan frontlight digunakan untuk memberikan pencahayaan pada beberapa display informatif sehingga pada area pameran pengunjung dapat membaca informasi dengan jelas. Pencahayaan light mapping digunakan pada area kolam untuk menunjang pertunjukan dancing water fountain. Lampu diproyeksikan ke air mancur yang bergerak.

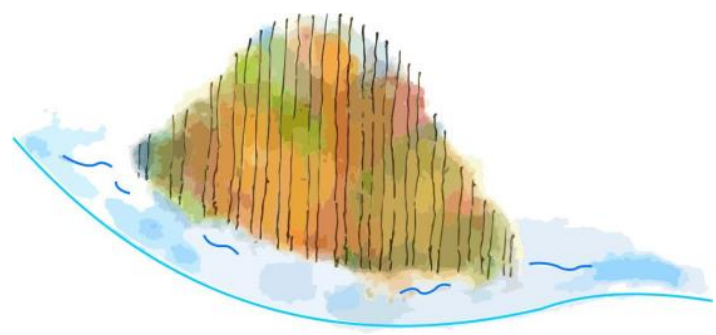

Gambar 20. Light Mapping

\subsection{Sistem Penghawaan}

Perancangan ini menggunakan sistem penghawaan alami dan buatan. Penghawaan alami memerlukan ventilasi seperti cross ventilation agar terjadi pergantian udara. Selain itu juga diperlukan penggunaan jendela, void, dan perletakan kolam air serta inner court untuk menyejukkan ruangan serta lingkungan bangunan. Perletakan kolam air merupakan salah satu penerapan prinsip berkelanjutan Biomorphic Architecture dengan penggunaan elemen air pada site, sedangkan inner court merupakan salah satu penerapan prinsip berkelanjutan Biomorphic Architecture dengan memanfaatkan vegetasi pada ruangan di dalam bangunan.
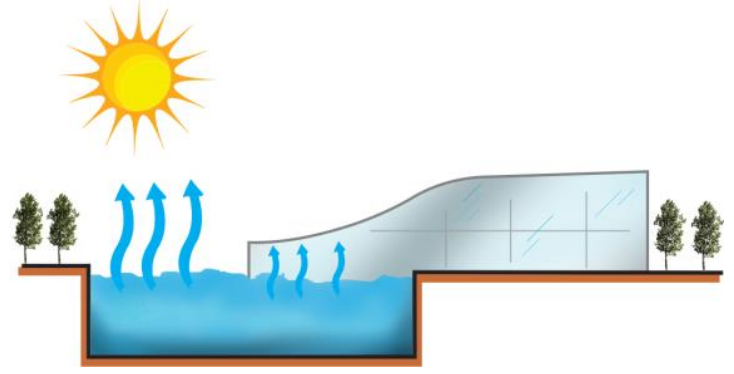

Gambar 21. Penghawaan Alami Kolam Air

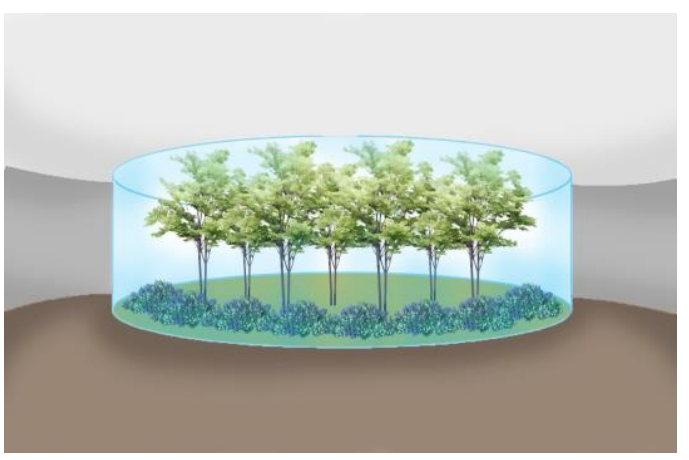

Gambar 22. Penghawaan Ala mi Inner Court 
Penghawaan buatan menggunakan dua jenis AC (Air Conditioner) yaitu AC Central dan AC Split. Penghawaan buatan dimanfaatkan pada ruangan yang lebih tertutup.

\subsection{Konsep Rencana Tapak}

Rencana tapak pada Oceanarium Pekanbaru terbagi menjadi 5 zona, yakni zona area utama dan parkir basement, zona bawah air, zona kolam, zona taman, dan zona parkir bus.

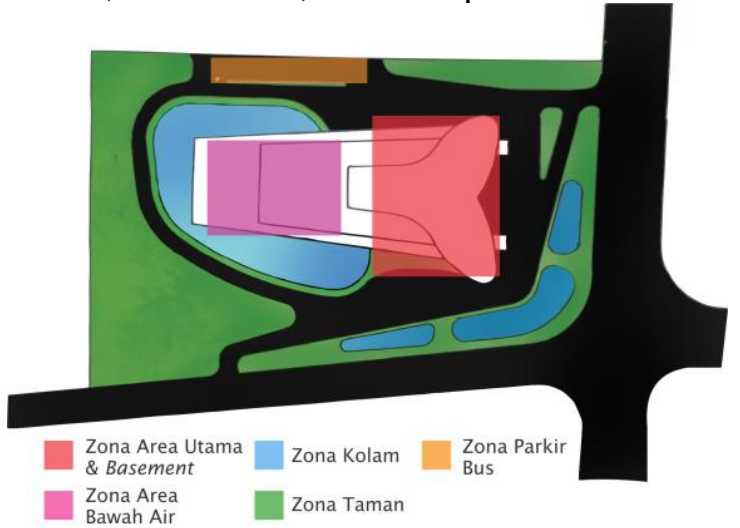

Gambar 23. Konsep Rencana Tapak

Pada zona kolam terdapat dancing water fountain yang merupakan pancuran air ke udara yang menggabungkan atraksi air, pencahayaan, serta irama musik. Penggunaan elemen air tersebut merupakan salah satu penerapan prinsip Biomorphic Architecture.

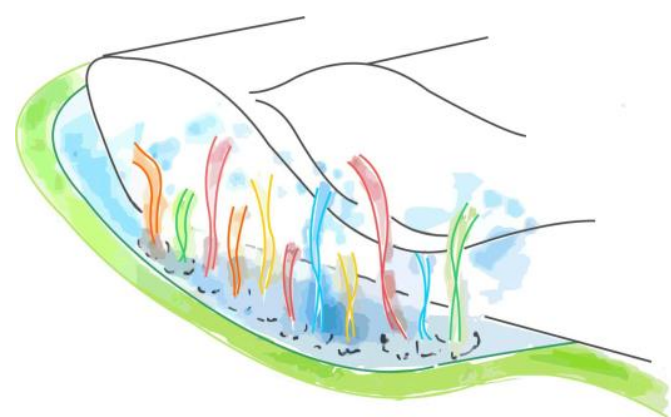

Gambar 24. Dancing Water Fountain

\subsection{Konsep Vegetasi}

Pemanfaatan vegetasi merupakan salah satu prinsip berkelanjutan pada Biomorphic Architecture. Konsep vegetasi pada Oceanarium Pekanbaru ini terdiri dari tanaman peneduh berada pada area tepi sirkulasi jalan di dalam site, tanaman peredam yang diletakkan pada area site yang berada di tepi jalan besar agar meredam suara dari kendaraan, serta tanaman penghias yang diletakkan pada area tepi kolam dan sekitar bangunan.

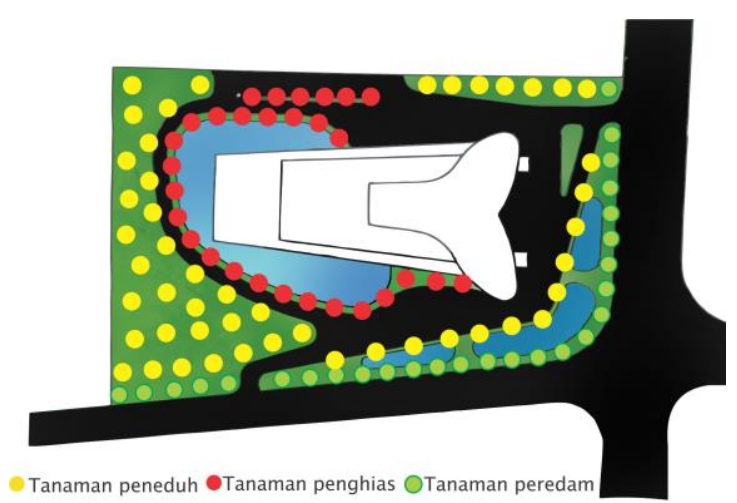

Gambar 25. Rencana Vegetasi

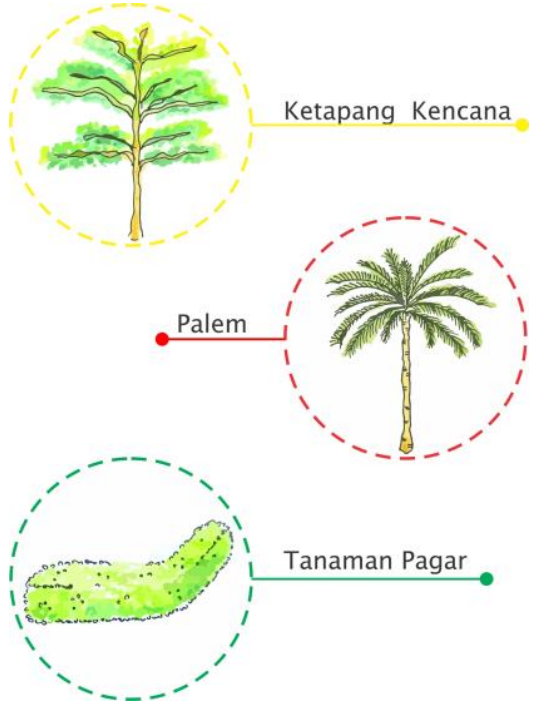

Gambar 26. Jenis Vegetasi

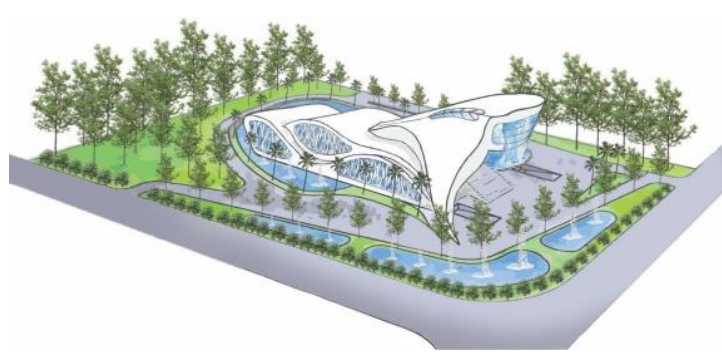

Gambar 27. Konsep Vegetasi

\section{KESIMPULAN}

Oceanarium Pekanbaru merupakan bangunan yang memiliki fungsi primer sebagai sarana rekreasi, edukasi, serta konservasi yang dilengkapi dengan fasilitas-fasiltas yang menunjang fungsi-fungsi tersebut. 
Penerapan pendekatan desain Biomorphic Architecture pada perancangan Oceanarium Pekanbaru dimulai dari konsep yang terinspirasi dari alam yakni kedinamisan dalam kehidupan bawah laut. Penerapan pendekatan desain Biomorphic Architecture selalu memperhatikan prinsip-prinsip yang ada. Prinsip yang pertama adalah bentuk yang didapatkan dari analogi atau metafora pada bentuk-bentuk alam. Penerapan bentuk pada perancangan Oceanarium Pekanbaru terinspirasi dari alam yang dinamis yakni transformasi dari bentuk ekor paus dan air laut yang merupakan salah satu simbol dari kehidupan laut. Prinsip selanjutnya adalah penggunaan struktur dan material yang lebih estetis dengan menggunakan bentuk-bentuk alam. Penerapan prinsip struktur menggunakan space frame agar dapat lebih estetis, serta dapat mendukung bentuk- bentuk kurvilinier sesuai dengan konsep yang diterapkan, sedangkan pada material lebih banyak menggunakan material alami seperti kayu pada interior serta fasad bangunan, material batu alam pada lantai dan pedestrian, material berbahan ringan seperti membrane, dan material lain yang mendukung bentuk- bentuk kurvilinier. Prinsip terakhir adalah prinsip berkelanjutan yang diterapkan pada penerapan efisiensi penggunaan energi yakni dengan memanfaatkan cahaya matahari sebagai pencahayaan alami di siang hari, pemanfaatan vegetasi pada site, serta penggunaan elemen air.

\section{REFERENSI}

Agkathidis, A. (2016). Implementing Biomorphic Design Design Methods in Undergraduate Architectural Education. ECAADE 2016: Complexity \& Simplicity, Vol.1, 1-8.

Akbar, Y. A. (2019). Siak River Aquatic Hub Di Pekanbaru Dengan Pendekatan Prinsip Desain Santiago Calatrava. Jurnal Online Mahasiswa Fakultas Teknik Universitas Riau, Vol. 6.

Angkouw, R., \& Kapugu, H. (2012). Ruang Dalam Arsitektur Berwawasan Perilaku. Media Matrasain, 1, Vol. 9, 58-74.

Augustyn, A., \& Bauer, P. (2013). Oceanarium. Encyclopedia Britannica. https://www.britannica.com/science/ocea narium

Badan Pusat Statistik Provinsi Riau. (2020). Provinsi Riau Dalam Angka 2020 (Bidang Integrasi Pengolahan dan Diseminasi Statistik (ed.)). BPS Provinsi Riau.

Baldwin, E. (2018). World Trade Center Transportation Hub Oculus Designed in Remembrance of 9/11. Archdaily. https://www.archdaily.com/901840/worl d-trade-center-transportation-hub-oculusdesigned-in-remembrance-of-9-11

Carone, G. B. L. (2018). Esplanade Complex. In Wikiarquitectura. https://en.wikiarquitectura.com/building/ esplanade-complex/

Coffeen, J., Jacquelin, F., \& Kepple, R. (2015). Georgia aquarium design space analysis and optimization. Procedia Computer Science, 44(C), 125-134. https://doi.org/10.1016/j.procs.2015.03.0 01

Dewan Perwakilan Rakyat Daerah Provinsi Riau, \& Gubernur Riau. (2018). Peraturan Daerah Provinsi Riau Nomor 10 Tahun 2018 Tentang Rencana Tata Ruang Wilayah Provinsi Riau Tahun 2018-2038. BAB VII Arahan Pemanfaatan Ruang Wilayah Provinsi, Pasal 41-45.

Direktorat Jenderal Penguatan Daya Saing Produk Kelautan dan Perikanan Kementerian Kelautan dan Perikanan. (2018). Potensi Usaha dan Peluang Investasi Kelautan dan Perikanan Provinsi Riau.

Harcourt, H. M. (2010). Webster's New World College Dictionary, 4th Edition.

Ishomuddin, M. (2013). Perancangan Sea World di Kawasan Wisata Bagari Lamongan. 10660016, 10-103.

Ishomuddin, M., \& Fikriarini, A. (2016). Biomorphic architecture approach in building form based on environmental concern. Jurnal Teknologi. https://doi.org/10.11113/jt.v78.8281

Jordana, S. (2010). Batumi Aquarium / Henning Larsen Architects. In Archdaily. https://www.archdaily.com/73022/batumi -aquarium-henning-larsen-architects

Lange. (1955). The Third Aquarium Congress. Murray, J. a H. (2015). A New English Dictionary on Historical Principles: 
Founded Mainly on the Materials Collected by the Philological Society (Vol. 8). Palala Press.

Rasikha, T. N. G. (2009). Arsitektur Organik Kontemporer. 25-47. lib.ui.ac.id/file?file=pdf/abstrak20249531.pdf

Sanjaya, E. A. (2015). Perancangan Oceanarium di Kawasan Wisata Pantai Parangtritis.

Santosa, F. (2018). Wilayah Geografis Pekanbaru. Pekanbaru.go.id - Portal Resmi Pemerintah Kota Pekanbaru. https://pekanbaru.go.id/p/hal/wilayahgeografis

Supardjo, S. (2014). Aplikasi arsitektur biomorfik dalam rancangan arsitektur. Media Matrasain, Vol. 11, No.1, 33-42.

Taha, R. I. (2019). Biomorphic Design for Interior Spaces In the 21 st century Riham Ismail Taha. June. https://doi.org/10.13140/RG.2.2.14212.1 7288

Tham, Y. (2019). Architecture \& Building Design.

https://www.esplanade.com/aboutus/architecture-and-building-design

Yulianingsih, F. (2011). Aquarium Biota Laut di Pantai Cermin (Arsitektur Metafora). http://repository.usu.ac.id/handle/123456 $789 / 27402$ 